\title{
Governança pública: avanços e retrocessos da política de ciência e tecnologia do Tocantins
}

\section{Jeany Castro dos Santos ${ }^{1}$ e Fernanda Rodrigues da Silva ${ }^{2}$}

1 Mestra e doutoranda em Desenvolvimento Regional pela Universidade Federal do Tocantins - UFT. Especialização em Elaboração e Gerenciamento de Projetos Públicos pela FAESP e Especialização em Formação de Professores para o Ensino Superior pela ULBRA. Bacharel em Sistemas de Informação pelo CEULP/ULBRA e Licenciada em Matemática pela UNITINS. Bolsista CNPQ EXP-B. Brasil. E-mail: jeanycastros@gmail.com

2 Mestra e Doutoranda em Desenvolvimento Regional pela Universidade Federal do Tocantins - UFT. Bacharel em Administração pela UFT - Campus Universitário de Palmas e Universidade Federal de Viçosa - UFV - Campus Viçosa, pelo Programa Santander de Mobilidade Acadêmica. Brasil. E-mail: nandasullyvan@gmail.com

RESUMO: Este artigo teve como objetivo avaliar o estágio de governança da Política de Ciência e Tecnologia no Tocantins (PCTT), bem como identificar os avanços e retrocessos desta política no período de 2005 a 2015. O estudo refere-se a uma pesquisa de natureza qualitativa e os instrumentos de coleta de dados utilizados foram pesquisa documental e entrevista semiestruturada. Para a interpretação dos dados aplicou-se o método da análise de conteúdo. A partir dos resultados, foi possível observar que as medidas adotadas pelo governo do Tocantins tiveram duas fases determinantes, a primeira avaliada como avanço da Política, mediante a criação da Secretaria Estadual de Ciência e Tecnologia (SECT), e da Fundação de Amparo à Pesquisa do Tocantins (FAPT), e a segunda percebida como retrocesso em que pese às medidas da desestruturação da SECT e inoperância da FAPT, neste sentido infere-se que governança nesta Política ainda está em estágio inicial.

Palavras-chave: Política Pública, Ciência e Tecnologia, Governança Pública.

Public governance: progress and setbacks of Tocantins science and technology policy ABSTRACT: This study aimed to evaluate the degree of governance of Science and Technology Policy in Tocantins (PCTT) and identify advances and setbacks of this policy from 2005 to 2015 . The study refers to a qualitative research and the data collect instruments used were documentary research and semistructured interview. For the data interpretation was applied the method of content analysis. From the results, it was possible to observe that the measures adopted by the Tocantins Government had two determinant phases, the first one it was evaluated as a policy advance, through the creation of the State Secretary of Science and Technology (SECT), and the Research Support Foundation Tocantins (FAPT), and the second perceived as backward in spite of the measures the disruption of SECT and ineffectiveness of FAPT. In this sense it appears that the degree of governance in this policy is still in early stage.

Keywords: Public Policy, Science and Technology, Public Governance.

\section{INTRODUÇÃO}

A partir da criação do Ministério da Ciência e Tecnologia (MCT) em 1985, buscou-se im- 
plantar em todo o país as Secretarias Estaduais de Ciência e Tecnologia (SECT). Com este direcionamento, a comunidade científica e tecnológica mobilizou-se para que na nova Constituição Federal constasse um dispositivo que permitisse aos governos estaduais vincular parcela de sua receita tributária às entidades públicas de fomento e à pesquisa científica e tecnológica, neste sentido, a Política de Ciência e Tecnologia (PCT) do Brasil foi alterada e os entes subnacionais passaram a ser corresponsáveis pela política.

No que se refere ao estado do Tocantins, faz-se oportuno registrar que o mesmo foi criado juntamente com a Constituição Federal de 1988, este aspecto é importante, pois o distingue dos demais estados brasileiros no que tange ao processo de estruturação da Política de Ciência e Tecnologia. O contexto político e econômico desse período sinalizava para uma administração mais descentralizada, com maior autonomia dos entes subnacionais. Apesar da situação propícia aos estados, diferentemente dos que já existiam antes da Constituição Federal de 1988, o Tocantins começa a criar os primeiros órgãos estaduais que dariam sustentação ao início da gestão da Política Estadual de Ciência e Tecnologia, enquanto os demais já gozavam de certa autonomia para desenvolver a PCT.

Somente dezessete anos depois de sua criação o estado do Tocantins inseriu na estrutura de governo um órgão específico para gerir a Ciência e Tecnologia (C\&T) - A secretaria de Ciência e Tecnologia (SECT). Entre os anos de 2005 e 2011 observa-se que importantes medidas foram adotadas pelo governo estadual com o objetivo de estruturar a Política Estadual de Ciência e Tecnologia, com destaque para a criação das seguintes instituições: SECT em 2005, Conselho Estadual de Ciência e Tecnologia (CECT) em 2006, Fundo Estadual de Ciência e Tecnologia (FECT) em 2007 e a Fundação de Amparo à Pesquisa do Tocantins (FAPT) em 2011.

O processo inverso ocorreu nos anos subsequentes, em 2012 a SECT foi desestruturada e juntamente com outras secretarias passaram a constituir a Secretaria de Desenvolvimento Econômico, Ciência, Tecnologia e Inovação (SDECT). O CECT teve sua última reunião realizada em 2012, e em 2013 a FAPT, apesar de ativa, tornou-se praticamente inoperante.

Diante do cenário exposto, este artigo teve como objetivo avaliar o grau de governança da PCTT, bem como identificar os seus avanços e retrocessos no período de 2005 a 2015.

A justificativa para este estudo consiste na ampliação das discussões sobre governança nas políticas públicas, neste caso, ousou-se avaliar a Ciência e Tecnologia, visto que a mesma compreende um mecanismo importante para o desenvolvimento do Estado, e que, no entanto, não recebeu o devido tratamento para que se institucionalizasse como uma política de médio e longo prazo.

O presente artigo encontra-se estruturado em cinco seções, incluindo esta introdução. A segunda apresenta o referencial teórico, contendo as interfaces dos diferentes conceitos atribuídos ao termo governança e sua relação com as políticas públicas. A seguinte apresenta os aspectos metodológicos utilizados para o desenvolvimento do trabalho. Na quarta seção está a análise dos resultados da pesquisa, e por fim, a quinta expõe as considerações finais. 


\section{ABORDAGENS TEÓRICAS}

A política pública constitui-se em um modelo de governança que envolve a participação dos entes federativos em ações que visam promover a gestão dos recursos em áreas de interesse público. A discussão que segue, foi estruturada em dois tópicos, o primeiro que discorre sobre o conceito de governança e o segundo que trata sobre a política de ciência e tecnologia.

\subsection{Governança pública: breve contextualização conceitual}

Para explicar o conceito de governança Nardes, Altounian e Vieira (2014, p.181) chamam a atenção para a necessidade de se conhecer a origem da palavra "governo". De acordo com a definição trazida pelos autores, a "expressão 'governo' origina da palavra grega kubernan que significa a parte superior do leme das embarcações. Portanto, a ideia de governo está atrelada à capacidade de direção ou definição de rumos corretos".

O conceito de governança pode ter várias interpretações a depender do objeto a ser investigado. Segundo o Banco Mundial, no documento Governace and Development publicado em 1992, governança é a maneira pela qual o poder é exercido na administração dos recursos sociais e econômicos de um país com vistas ao desenvolvimento. Este consiste na capacidade dos governos de planejar, formular e programar políticas, bem como de cumprir suas funções (NARDES; ALTOUNIAN; VIEIRA, 2014).

Governança muitas vezes é interpretada como sinônimo de governo. No entanto, Rosenau (2000, p.15) esclarece que "governança não é o mesmo que governo". O autor explica que

Governo sugere atividades sustentadas por uma autoridade formal, pelo poder de polícia que garante a implementação das políticas devidamente instituídas, enquanto governança refere-se a atividades apoiadas em objetivos comuns, que podem ou não derivar de responsabilidades legais e formalmente prescritas e não dependem necessariamente do poder de polícia para que sejam aceitas e vençam a resistência (ROSENAU, 2000, p.15).

Esta distinção entre governo e governança é reforçada por Perez (2003) quando relaciona o conceito de governança às instituições deliberativas, para o autor é necessário que haja espaços de discussão entre os agentes públicos e a sociedade para que ocorra a priorização de ações em favor do desenvolvimento não só econômico, mas principalmente social.

Para avançar na discussão rumo ao conceito mais adequado à abordagem deste estudo, a governança pública pode ser entendida como a capacidade que os governos têm de avaliar, direcionar e monitorar a gestão das políticas públicas para atender de forma efetiva as necessidades da população. Ainda de acordo com Nardes, Altounian e Vieira (2014, p.208) a boa governança implica em traduzir em ações as necessidades da população orientada pelos ditames constitucionais: 
Países que apresentam bons sistemas de governo possuem melhor nível de confiança político, econômico e social [...] e acabam por atrair maior volume de recursos de investimentos internos e externos para o seu crescimento e consequente melhoria dos indicadores de qualidade de vida (NARDES; ALTOUNIAN; VIEIRA, 2014, p.208).

Outra definição de governança que segue a mesma linha de pensamento foi emitida pelo $\operatorname{TCU}(2013$, p.18):

Governança no setor público compreende essencialmente os mecanismos de liderança, estratégia e controle postos em prática para avaliar, direcionar e monitorar a atuação da gestão, com vistas à condução de políticas públicas e à prestação de serviços de interesse da sociedade.

Governança seria o mesmo que boa governança. A má governança pode ser entendida com a ausência de governança. A governança não é ação isolada da sociedade civil buscando maiores espaços de participação e influência. Ao contrário, o conceito compreende a ação conjunta de Estado e sociedade na busca de soluções e resultados para problemas comuns (TCU, 2013).

Contudo, Nardes, Altounian e Vieira (2014, p.182) afirmam que o conceito de governança é substantivo, ou seja, deve-se considerar uma gradação quando analisa-se cada caso concreto. Sempre haverá governança, por mais inicial que seja o seu estágio. A discussão está na qualidade (boa, regular ou ruim) ou no estágio (avançado, intermediário ou inicial) em que se encontra.

Para este artigo, optou-se verificar o estágio da governança pública da Política de Ciência e Tecnologia no Estado do Tocantins (PCTT), com base nos estágios arrolados no quadro 1.

Quadro 1: Detalhamento dos estágios da governança

\begin{tabular}{|c|l|}
\hline Estágios da Governança & \multicolumn{1}{c|}{ Descrição } \\
\hline Inicial & $\begin{array}{l}\text { Quando ocorre o menor envolvimento da alta administração, planejamento mais frágil, servidores } \\
\text { menos preparados, controles internos menos rigorosos e menos estruturado, tem-se uma gover- } \\
\text { nança inicial. }\end{array}$ \\
\hline \multirow{3}{*}{ Intermediária } & $\begin{array}{l}\text { Quando a alta administração tem conhecimento de seu papel e está preocupada em dar firme } \\
\text { direção à instituição por meio de planejamento, reconhecendo a necessidade de pessoal qualifica- } \\
\text { do para assumir processos e controles de processos mais rigorosos, tem-se uma governança inter- } \\
\text { mediária. }\end{array}$ \\
\hline Avançada & $\begin{array}{l}\text { Quanto encontram-se evidências do elevado compromisso da alta administração com a direção da } \\
\text { instituição em todos os níveis, por meio de planejamento consistente e sistemático, fixação clara de } \\
\text { objetivos e metas, monitoração da execução e auditoria, tem-se uma governança avançada. }\end{array}$ \\
\hline
\end{tabular}

Fonte: Elaboração própria com base na TC 000.390/2010-0, p. 34, 35.

Melhorar a governança pública significa ouvir a população, planejar melhor, ter bons processos de trabalho, escolher servidores públicos com critérios, ter indicadores que possam ser mensurados e melhorados continuamente, articular a atuação dos diversos agentes sociais, divulgar com total transparência os resultados alcançados e, consequentemente, criar condições favoráveis para investimentos internos e externos e para o desenvolvimento nacional sustentável (NARDES; ALTOUNIAN; VIEIRA, 2014).

Evans (2003, p.46) considera que a existência de instituições deliberativas são essenciais 
para o estabelecimento da governança ao afirmar que "uma das mais importantes consequências das instituições deliberativas é 'suspender' as barreiras quanto à transparência e a responsabilidade final do aparato estatal".

De acordo com Nardes, Altounian e Vieira (2014, p.182) são oito as principais características da boa governança: "Estado de direito, transparência, responsabilidade, orientação por consenso, igualdade e inclusividade, efetividade e eficiência e prestação de contas".

É a partir de tais princípios que a gestão pública pode avançar em níveis de confiança da população, e com isto proporcionar as condições para que tanto o poder público quanto a sociedade civil alcancem elevados níveis de pertencimento que resultem em baixos percentuais de ineficiência decorrente de decisões unilaterais e da diminuição da corrupção (EVANS, 2003). Neste sentido, o tópico seguinte traz contribuições em relação à decisão política, necessárias à discussão dos dados empíricos.

\subsection{A decisão política como fator determinante para o desenvolvimento científico e tecnológico}

A Sociologia e a Ciência Política oferecem contribuições importantes em relação à política de ciência e tecnologia, pois consideram aspectos relacionados ao processo de tomada de decisão. Neste sentido, "[...] apesar de terem várias dimensões, seus fundamentos são essencialmente políticos" (BENAKOUCHE, 2012, p.20), pois envolvem questão de participação pública na ciência e na formação voltada para a ciência e tecnologia.

Um aspecto que dificulta os avanços nesta área, diz respeito à ordem metodológica "não há um modelo de intervenção pronto ou livre de dificuldades [...], no caso consideram dois eixos de ação - o da participação na ciência e o da participação na política - propondo que há um ponto de cruzamento entre os dois" (BENAKOUCHE, 2012, p. 21). Longe de ser um consenso, a participação depende de forma direta da tomada de decisão ou de decisões políticas.

Para entender "quem ou o quê formula políticas, é preciso entender as características dos participantes, os papéis que desempenham a autoridade e os outros poderes que detêm, como lidam uns com os outros e se controlam mutuamente" (LINDBLOM, 1981, p.8, grifos nosso).

O processo de decisão política, muitas vezes influenciado por acordos, barganhas e interesses não são determinantes em termos de resultados quando da adoção de uma política em detrimento de outra, para Lindblom (1981, p.12) "os fatores socioeconômicos, como a riqueza do Estado, e o seu nível de industrialização" é que definem as políticas que serão priorizadas. Para o autor, a sociedade é que demanda suas necessidades e estabelece os objetivos políticos e não a decisão política. O processo decisório explica, em parte, como os governos definem as políticas, mas não por que foram levados a escolher uma situação em detrimento de outra. O estudo realizado por Benakouche (2012) segue uma linha de pensamento bem próxima da discutida anteriormente.

Com base em Trigueiro (2009) a discussão sobre a C\&T, a partir de uma conexão com os 
atores sociais responsáveis pela sua expansão, visa trazer contribuições no que se refere às teorias e aos métodos de pesquisa para os estudos de C\&T com base na perspectiva da sociologia. Neste sentido, no Brasil, a popularização da ciência começa a ser encarada como um instrumento para tornar disponíveis conhecimentos e tecnologias que ajudam a melhorar a vida das pessoas e que dão suporte a desenvolvimentos econômicos e sociais sustentáveis (BAUMGARTEN, 2012).

O discurso predominante é que, sem $C \& T$, não há inovação e progresso, e consequentemente, não se alcançam níveis de competitividade mundial. O problema do Brasil é que a ciência básica é desenvolvida quase que inteiramente em universidades e institutos de pesquisas. Apesar do discurso sobre a importância do financiamento privado para a ciência básica, todos os dados disponíveis no mundo mostram que este subsistema é financiado majoritariamente com recursos públicos.

O financiamento para a ciência básica pode ter áreas que são privilegiadas no tempo, mas o sistema depende de um financiamento harmônico, que cubra essencialmente todas as áreas do conhecimento. A decisão política sobre esta linha de financiamento é uma decorrência da compreensão, em nível de Estado, da correlação entre a produção de ciência básica e os outros sistemas que conduzem ao desenvolvimento socialmente justo (CHAIMOVICH, 2000).

O conhecimento científico e tecnológico e os processos de inovação econômico e social que deles decorrem, podem ser instrumentos estratégicos para a promoção de desenvolvimento sustentável, para a inclusão social e para a redução das desigualdades sociais e regionais em países historicamente marcados pela desigualdade como o Brasil (BAUMGARTEN, 2012).

Mesmo diante de limitações tão significativas, o Brasil avança no campo da C\&T, esta constatação é registrada por Canales (2011, p. 13, tradução nossa), como segue:

[...] o Brasil, um dos países da América Latina com os melhores indicadores e as melhores capacidades no setor, procurou orientar as suas políticas, desde os anos noventa, na área de C\&T, por meio da competitividade industrial, caracterizada por um aumento da concorrência no ambiente de mercado e do desenvolvimento de uma indústria baseada na ciência.

As escolhas políticas, a capacidade de reivindicação e de debate em torno de melhorias sociais e questões estratégicas como energia, saúde, problemas urbanos, violência, entre outras, também envolvem informação e conhecimento, o que remete para a importância do debate sobre como o conhecimento é produzido.

A problemática abordada por Cabrero (2006) reforça o posicionamento de Lindblom (1981) quando afirma que o contexto social determina as decisões políticas. Entender a relevância da C\&T para o desenvolvimento do Tocantins parece central quando se analisa os investimentos em C\&T. Outro aspecto bastante relevante diz respeito às características próprias da ciência e o que a academia considera relevante investigar.

O descompasso impacta profundamente nos resultados alcançados pelas C\&T no Brasil, uma vez que os interesses dos tomadores de decisão podem ser diferentes dos interesses 
dos que realizam as pesquisas, e que por sua vez também são distintos dos beneficiários das pesquisas (RODRIGUES, 2013).

Estas considerações nos conduzem à ideia de que inclusão social, econômica, política e desenvolvimento da cidadania dependem, na atualidade, da educação científica, do conhecimento social sobre C\&T e das necessidades sociais. Democratizar informações é obter apoio político para a produção de conhecimentos científicos, e a ampliação de possibilidades tecnológicas (BAUMGARTEN, 2012, p.95).

Apesar de a temática das relações entre ciência e tecnologia ter sido ampliada nas duas ultimas décadas, a comunicação pública sobre C\&T e as atividades de divulgação de C\&T não têm recebido a atenção necessária por parte de produtores e gestores do conhecimento no Brasil. Um indicador desta realidade pode ser observado nas atividades de difusão, extensão e de educação científica, as mesmas não são adequadamente valorizadas nas instituições de pesquisa e nas universidades, nem mesmo nas agências de fomento e gestão de C\&T (BAUMGARTEN, 2012).

As articulações entre o campo de produção de C\&T e a sociedade são complexas, dinâmicas e interativas, sua dinâmica constitui-se em um dos grandes desafios para os cientistas e a sociedade. Atualmente, não há no Brasil, uma adequada transferência e utilização social dos conhecimentos produzidos nas instituições de pesquisa, notadamente nas universidades, o que contribui para a relativa distância entre sociedade e a academia. As pesquisas produzidas nas universidades são pouco aproveitadas em favor da superação dos problemas sociais. Este aspecto dificulta a identificação e acolhimento adequado das necessidades e demandas da sociedade ao setor de C\&T (BAUMGARTEN, 2012, p.96).

Neste tópico constatou-se que a decisão política é diretamente influenciada pelo contexto social. Há que se considerar que no Brasil há um número considerável de produções, no entanto, não são devidamente aproveitadas tampouco conhecidas do grande público. Esta questão apresentou-se como central para a compreensão do processo de tomada de decisão.

Na seção seguinte serão apresentados os procedimentos metodológicos.

\section{Procedimentos Metodológicos}

A coleta de dados ocorreu por meio das seguintes estratégias metodológicas: pesquisa documental e entrevistas semiestruturada, as mesmas serão devidamente apresentadas a seguir.

\subsection{Procedimentos para a realização da pesquisa documental}

A pesquisa documental é a técnica de coleta de dados que se utiliza de material que ainda não recebeu tratamento analítico, ou que podem ser reelaborados de acordo com o objetivo da pesquisa (PRODANOV; FREITAS, 2013). Desta forma, os documentos utilizados para análise documental constam do Quadro 1 que teve como objetivo descrever os avanços e retrocessos da política de C\&T no Tocantins. 
Quadro 1: Lista dos documentos analisados

\begin{tabular}{|c|c|c|c|}
\hline Documentos & Tipo & Órgão Responsável & Ano \\
\hline Constituição do Estado do Tocantins & Constituição & Assembleia Legislativa & 1988 \\
\hline Lei 780 de 02 de outubro de 1995 & Lei & Assembleia Legislativa & 1995 \\
\hline Lei 1039 de 22 de dezembro de 1998 & Lei & Assembleia Legislativa & 1998 \\
\hline Lei 1664 de 22 de fevereiro de 2006 & Lei & Assembleia Legislativa & 2006 \\
\hline $\begin{array}{l}\text { Relatório do processo de descentralização e fomento } \\
\text { à ciência, tecnologia e inovação no Brasil. }\end{array}$ & Relatório & Centro de Gestão e Estudos Estratégico & 2010 \\
\hline $\begin{array}{l}\text { Plano de Ciência, Tecnologia e Inovação para o De- } \\
\text { senvolvimento da Amazônia. }\end{array}$ & Relatório & Centro de Gestão e Estudos Estratégico & 2013 \\
\hline Relatório financeiro & Relatório & Ministério do Planejamento & 2015 \\
\hline Relatório Financeiro & Relatório & Ministério da Ciência e Tecnologia & 2015 \\
\hline Constituição do Estado do Tocantins & Constituição & Assembleia Legislativa & 1989 \\
\hline Lei no 780, de 02 de outubro de 1995. & Lei & $\begin{array}{l}\text { Criação do Conselho Estadual de Ciên- } \\
\text { cia e Tecnologia }\end{array}$ & 1995 \\
\hline $\begin{array}{l}\text { Decreto no } 2588 / 2005 \text { - Institui a Secretaria de Ciên- } \\
\text { cia e Tecnologia }\end{array}$ & Decreto & $\begin{array}{l}\text { Secretaria Estadual de Ciência e Tecno- } \\
\text { logia do Tocantins }\end{array}$ & 2005 \\
\hline $\begin{array}{l}\text { Ato no } 706 / 2006 \text { - Nomeação do Secretário da SECT } \\
\text { - João Leite Neto }\end{array}$ & Ato & $\begin{array}{l}\text { Secretaria Estadual de Ciência e Tecno- } \\
\text { logia do Tocantins }\end{array}$ & 2006 \\
\hline $\begin{array}{l}\text { Decreto no } 2694 \text { - Dispõe sobre a SECT - Republica- } \\
\text { ção }\end{array}$ & Decreto & $\begin{array}{l}\text { Secretaria Estadual de Ciência e Tecno- } \\
\text { logia do Tocantins }\end{array}$ & 2007 \\
\hline $\begin{array}{l}\text { Ato no } 62 \text { - Nomeação do Secretário da SECT - José } \\
\text { Augusto Pires Pares }\end{array}$ & Ato & $\begin{array}{l}\text { Secretaria Estadual de Ciência e Tecno- } \\
\text { logia do Tocantins }\end{array}$ & 2007 \\
\hline $\begin{array}{l}\text { DOU no } 2336 \text { - Estrutura da SECT e Vinculação da } \\
\text { CECT à SECT }\end{array}$ & DOU & $\begin{array}{l}\text { Secretaria Estadual de Ciência e Tecno- } \\
\text { logia do Tocantins }\end{array}$ & 2007 \\
\hline $\begin{array}{l}\text { Ato no } 2357 \text { - Nomeação do Secretário da SECT - } \\
\text { Osmar Nina Garcia Neto }\end{array}$ & Ato & $\begin{array}{l}\text { Secretaria Estadual de Ciência e Tecno- } \\
\text { logia do Tocantins }\end{array}$ & 2007 \\
\hline $\begin{array}{l}\text { Ato no } 3052 \text { - Nomeação da Secretária da SECT - } \\
\text { Maria Fernanda Varanda Carneiro }\end{array}$ & Ato & $\begin{array}{l}\text { Secretaria Estadual de Ciência e Tecno- } \\
\text { logia do Tocantins }\end{array}$ & 2009 \\
\hline $\begin{array}{l}\text { Ato no } 2510 \text { - Nomeação da Secretária da SECT - } \\
\text { Márcia Izabel Barbosa Soares }\end{array}$ & Ato & $\begin{array}{l}\text { Secretaria Estadual de Ciência e Tecno- } \\
\text { logia do Tocantins }\end{array}$ & 2010 \\
\hline Estrutura da SECT & Ato & $\begin{array}{l}\text { Secretaria Estadual de Ciência e Tecno- } \\
\text { logia do Tocantins }\end{array}$ & 2011 \\
\hline $\begin{array}{l}\text { Ato no } 11 \text { - Nomeação do Secretário da SECT - Luiz } \\
\text { Carlos Borges da Silveira }\end{array}$ & Ato & $\begin{array}{l}\text { Secretaria Estadual de Ciência e Tecno- } \\
\text { logia do Tocantins }\end{array}$ & 2011 \\
\hline $\begin{array}{l}\text { Ato no } 1266 \text { - Nomeação daPresidente da FAPT - } \\
\text { Andrea Noleto do Souza Stival }\end{array}$ & Ato & $\begin{array}{l}\text { Secretaria Estadual de Ciência e Tecno- } \\
\text { logia do Tocantins }\end{array}$ & 2011 \\
\hline $\begin{array}{l}\text { Ato no } 1945 \text { - Designação do Conselho Curador da } \\
\text { FAPT }\end{array}$ & Ato & $\begin{array}{l}\text { Secretaria Estadual de Ciência e Tecno- } \\
\text { logia do Tocantins }\end{array}$ & 2011 \\
\hline Decreto no 4576 - Execução orçamentária financeira & Decreto & $\begin{array}{l}\text { Secretaria Estadual de Ciência e Tecno- } \\
\text { logia do Tocantins }\end{array}$ & 2012 \\
\hline $\begin{array}{l}\text { Ato no } 1960 \text { - Nomeação daSecretário da SECT - } \\
\text { Andrea Noleto de Souza Stival }\end{array}$ & Ato & $\begin{array}{l}\text { Secretaria Estadual de Ciência e Tecno- } \\
\text { logia do Tocantins }\end{array}$ & 2012 \\
\hline $\begin{array}{l}\text { Ato no } 316 \text { - Nomeação do Secretário da SEDECTI - } \\
\text { Paulo Henrique Ferreira Massuia }\end{array}$ & Ato & $\begin{array}{l}\text { Secretaria Estadual de Ciência e Tecno- } \\
\text { logia do Tocantins }\end{array}$ & 2013 \\
\hline $\begin{array}{l}\text { Medida Provisória no } 01 \text { - Fusão da SECT com a SIC - } \\
\text { Criação da SEDECTI }\end{array}$ & Medida Provisória & $\begin{array}{l}\text { Secretaria Estadual de Ciência e Tecno- } \\
\text { logia do Tocantins }\end{array}$ & 2013 \\
\hline $\begin{array}{l}\text { Ato no } 485 \text { - Nomeação do Secretário Executivo } \\
\text { Marcos Jair }\end{array}$ & Ato & $\begin{array}{l}\text { Secretaria Estadual de Ciência e Tecno- } \\
\text { logia do Tocantins }\end{array}$ & 2013 \\
\hline DOU 3842 - Estrutura da SEDECTI & DOU & $\begin{array}{l}\text { Secretaria Estadual de Ciência e Tecno- } \\
\text { logia do Tocantins }\end{array}$ & 2013 \\
\hline $\begin{array}{l}\text { Ato no } 803 \text { - Nomeação do Presidente da FAPT - } \\
\text { Paulo Henrique Ferreira Massuia }\end{array}$ & Ato & $\begin{array}{l}\text { Secretaria Estadual de Ciência e Tecno- } \\
\text { logia do Tocantins }\end{array}$ & 2013 \\
\hline 3857 - Incorporação da SEDECTI & DOU & $\begin{array}{l}\text { Secretaria Estadual de Ciência e Tecno- } \\
\text { logia do Tocantins }\end{array}$ & 2013 \\
\hline $\begin{array}{l}\text { Lei Complementar no } 85 \text { - Presidência da FAPT exer- } \\
\text { cida cumulativamente com a SEDECTI }\end{array}$ & Lei complementar & $\begin{array}{l}\text { Secretaria Estadual de Ciência e Tecno- } \\
\text { logia do Tocantins }\end{array}$ & 2013 \\
\hline
\end{tabular}

Fonte: Elaboração própria. 


\subsection{Procedimentos para a realização das entrevistas e aplicação de questionários}

De acordo com Triviños (1987) a entrevista semiestruturada é uma técnica de coleta de dados que parte de certos questionamentos básicos, apoiados em teorias e hipóteses que interessam à pesquisa e que vão sendo reveladas à medida que os informantes verbalizam suas respostas. As pessoas entrevistadas foram escolhidas de acordo com a sua participação no processo de tomada de decisão na política de C\&T no Tocantins. As pessoas entrevistadas foram um governador, três secretários de Ciência e Tecnologia, um técnico, quatro membros do CECT e dois membros de instituições de pesquisa. Vale ressaltar, que em virtude do sigilo, os entrevistados foram citados pelas siglas que vai de E1 a E10. Para cada público foi elaborado um roteiro específico. $O$ objetivo com a realização das entrevistas foi analisar a percepção dos entrevistados quanto aos avanços e retrocessos da política de C\&T do Tocantins.

Importante informar, que além das entrevistas realizadas com o público citado anteriormente, efetivou-se, no dia 10 de dezembro de 2014, uma entrevista exploratória com o diretor do departamento de ciência, desenvolvimento, tecnologia e inovação da Agência Tocantinense de Ciência Tecnologia e Inovação (AGENTEC), selecionado a partir da função estratégica que exercia no órgão. As entrevistas foram executadas entre o dia 19 de junho e 19 de agosto de 2015. Todas as entrevistas foram gravadas em forma de áudio e transcritas na íntegra em seguida. Como a transcrição compreende a fase de pré-análise, as mesmas foram realizadas pelo próprio pesquisador. Somente por meio do áudio, outra pessoa, que não tenha participado da entrevista, não conseguiria internalizar as várias outras informações advindas da escuta de uma entrevista. Este foi um dos argumentos principais a favor da realização da transcrição pelo próprio entrevistador.

Desde a definição dos participantes da pesquisa até a análise das falas dos entrevistados, buscou-se encontrar respostas para o problema de pesquisa, para tanto, foram elaborados quatro roteiros diferentes de entrevistas, visando extrair com maior riqueza de detaIhes o que cada público poderia revelar em relação à percepção sobre o assunto.

Cabe esclarecer que nem todas as perguntas foram realizadas, uma vez que o entrevistado, em algumas situações, atendeu às expectativas de determinadas perguntas em questão anterior. Importante ressaltar que não foi intenção da pesquisa entrevistar um percentual expressivo das pessoas que atuam na política de C\&T no Tocantins, e sim analisar a percepção de pessoas que participaram diretamente das decisões ou de alguma forma influencia no processo de tomada de decisão. De acordo com Colognese e Melo (1998, p. 145) "mais importante que o número de entrevistados é a sua posição privilegiada no contexto das relações sociais em abordagem".

\subsection{Análise dos Dados}

A análise dos documentos teve como objetivo levantar os elementos que pudessem ser úteis às discussões propostas no problema de pesquisa. Para tanto, na análise das entrevistas foi utilizada a técnica de análise de conteúdo, desenvolvida por Laurence Bardin, que 
visa a interpretação de conhecimentos relativos ao objeto da pesquisa, por meio de procedimentos sistemáticos e objetivos, agrupados em categoria empiricamente definida ou não (BARDIN, 2011).

A partir dos dois objetivos propostos por Bardin (2011, p. 35) optou-se pela 'superação da incerteza' que consiste em analisar se "o que eu julgo ver na mensagem estará lá efetivamente contido, podendo esta 'visão' muito pessoal ser partilhada por outro? Por outras palavras será a minha leitura válida e generalizável?". No que se refere à função delimitada por Bardin, julga-se a mais adequada para a investigação deste trabalho, a 'função heurística' que compreende a "[...] tentativa exploratória, [aumento da] propensão para a descoberta. É a análise de conteúdo 'para ver no que dá'” (BARDIN, 2011, p. 35).

Bardin (2011) adverte que para a utilização do método da categorização é necessário obedecer à fragmentação da comunicação para que a análise seja válida, dessa forma, optou-se pela utilização das regras homogêneas (separar por núcleo de sentido), exclusivas (um elemento do conteúdo deve ficar em apenas uma categoria de análise, pois o objetivo é que todos levem a um único resultado) e adequadas ou pertinentes (ao conteúdo e ao objetivo da investigação). A escolha da técnica da análise de conteúdo se justifica pela possibilidade de o investigador analisar os dados a partir de inferências que podem ser confirmadas ou refutadas.

A técnica é recorrentemente utilizada devido à abrangência dos mecanismos que conforme aponta Bardin (2011, p. 37) "não se trata de um instrumento, mas de um leque de apetrechos; ou com maior rigor, será um único instrumento, mas marcado por uma grande disparidade de formas e adaptável a um campo de aplicação muito vasto: as comunicações".

Dentre o leque de possibilidades oferecidas pela técnica de análise de conteúdo, será adotada para este artigo a análise categorial que consiste em:

Tomar em consideração a totalidade de um "texto", passando-o pelo crivo da classificação e do recenseamento, segundo frequência de presença (ou de ausência) de itens de sentido. Isso pode constituir um primeiro passo, obedecendo ao princípio de objetividade e racionalizando por meio de números e percentagem uma interpretação que, sem ela, teria de ser sujeita a aval. É o método das categorias, espécie de gavetas ou rubricas significativas que permitem a classificação dos elementos de significação constitutivos da mensagem. [...] A técnica consiste em classificar os diferentes elementos nas diversas gavetas segundo critérios suscetíveis de fazer surgir um sentido capaz de introduzir alguma ordem na confusão inicial. É evidente que tudo depende, no momento da escolha dos critérios de classificação, daquilo que se procura ou que se espera encontrar [...] (BARDIN, 2011, p. 42 - 43).

Desta forma, como já mencionado, os pressupostos compreendem aquilo que está sendo procurado, e por esta razão, representarão na análise de conteúdo as "categorias". Para a criação das categorias foram realizadas várias leituras das entrevistas, para cumprir rigorosamente o método, que compreende as etapas de seleção e exploração do material; codificação, definição da unidade de registro, definição das unidades de análise, presençaausência, recorrência, intensidade, direção, ordem e sentido; definição dos índices; agrupamento dos temas e definição das categorias empíricas (BARDIN, 2011). A partir do exer- 
cício descrito, foram criadas as categorias descritas no Quadro 2, que serão exploradas no capítulo referente à discussão e análise dos dados.

Quadro 2: Categorias e principais apontamentos dos entrevistados

\begin{tabular}{|c|c|c|c|}
\hline $\begin{array}{l}\text { Categoria I - A política nacional } \\
\text { de descentralização de fomento } \\
\text { à C\&T }\end{array}$ & $\begin{array}{l}\text { Categoria II - O impacto } \\
\text { das relações intergover- } \\
\text { namentais na PC\&TT }\end{array}$ & $\begin{array}{l}\text { Categoria III - A instituciona- } \\
\text { lização da PC\&TT }\end{array}$ & $\begin{array}{l}\text { Categoria IV - Percepções } \\
\text { sobre o impacto das decisões } \\
\text { políticas sobre a C\&T }\end{array}$ \\
\hline $\begin{array}{l}\text { Nesta categoria constam os } \\
\text { relatos que descrevem a des- } \\
\text { centralização de fomento à C\&T } \\
\text { adotado pelo governo federal. } \\
\text { Os principais apontamentos } \\
\text { realizados pelos entrevistados } \\
\text { foram: } \\
\text { - Os percentuais do fundo } \\
\text { nacional de C\&T determinados } \\
\text { para região norte não são apli- } \\
\text { cados na prática; } \\
\text { - Os percentuais de contrapar- } \\
\text { tida exigidos pelo governo } \\
\text { federal são incompatíveis com } \\
\text { a realidade dos estados perifé- } \\
\text { ricos; } \\
\text { - A PNC\&T não consegue aten- } \\
\text { der às disparidades regionais; } \\
\text { - Os estados acabam desenvol- } \\
\text { vendo ações parametrizadas na } \\
\text { política do governo federal; } \\
\text { - Grande parte dos recursos é } \\
\text { repassada pelo governo federal } \\
\text { via encomenda e não por pro- } \\
\text { cesso seletivo; } \\
\text { - O Estado do Tocantins não } \\
\text { tem capacidade financeira para } \\
\text { propor suas próprias PC\&T. }\end{array}$ & $\begin{array}{l}\text { Nesta categoria contem- } \\
\text { plam relatos sobre o } \\
\text { impacto das relações } \\
\text { intergovernamentais na } \\
\text { PC\&TT. Os principais } \\
\text { apontamentos realizados } \\
\text { pelos entrevistados fo- } \\
\text { ram: } \\
\text { - a PC\&TT é dependente } \\
\text { das orientações políticas e } \\
\text { ideológicas de cada go- } \\
\text { verno (tanto estadual } \\
\text { quanto federal), em con- } \\
\text { sequência, compromete a } \\
\text { continuidade das políticas } \\
\text { já implementadas; } \\
\text { - Nos primeiros anos de } \\
\text { criação do estado do } \\
\text { Tocantins não houve } \\
\text { apoio do governo federal } \\
\text { para implantação da } \\
\text { PC\&T; } \\
\text { - O sistema tributário } \\
\text { está centralizado na Uni- } \\
\text { ão. }\end{array}$ & $\begin{array}{l}\text { Esta categoria contempla } \\
\text { relatos que evidenciam a } \\
\text { preocupação com a estrutura } \\
\text { de C\&T no estado. Os princi- } \\
\text { pais apontamentos realiza- } \\
\text { dos pelos entrevistos foram: } \\
\text { - os avanços decorrentes da } \\
\text { criação da SECT e da FAPT; } \\
\text { - a preocupação com o } \\
\text { futuro da C\&T no estado do } \\
\text { Tocantins depois da extinção } \\
\text { da SECT e da FAPT; } \\
\text { - a necessidade de infraes- } \\
\text { trutura física, técnica e finan- } \\
\text { ceira da SECT e da FAPT; } \\
\text { - as decisões do conselho } \\
\text { refletem apenas a vontade } \\
\text { do governo em virtude de ser } \\
\text { maioria; } \\
\text { - os recursos do FECT não } \\
\text { são utilizados nas suas ativi- } \\
\text { dades fim; } \\
\text { - os recursos são contingen- } \\
\text { ciados com frequência. }\end{array}$ & $\begin{array}{l}\text { Nesta categoria constam rela- } \\
\text { tos sobre as percepções dos } \\
\text { atores locais em relação ao } \\
\text { impacto das decisões políticas } \\
\text { sobre a C\&T no Tocantins. Os } \\
\text { principais apontamentos reali- } \\
\text { zados pelos entrevistos foram: } \\
\text { - os entraves para o desen- } \\
\text { volvimento da ciência, por } \\
\text { meio de pesquisas; à desconti- } \\
\text { nuidade das políticas imple- } \\
\text { mentadas; } \\
\text { - a não existência de um } \\
\text { planejamento da política esta- } \\
\text { dual de ciência e tecnologia de } \\
\text { médio e longo prazo, o que } \\
\text { ocasionou a paralização de } \\
\text { muitas pesquisas em momen- } \\
\text { tos de crise; } \\
\text { - as decisões políticas sobre } \\
\text { ciência e tecnologia no estado } \\
\text { não são tomadas com base em } \\
\text { um diagnóstico de pesquisas } \\
\text { prioritárias para o desenvolvi- } \\
\text { mento da região que, portan- } \\
\text { to, deveriam receber mais } \\
\text { investimentos. }\end{array}$ \\
\hline
\end{tabular}

Fonte: Elaboração própria, com base em Bardin (2011).

As etapas descritas pelo método foram cumpridas mediante a construção e aplicação de uma planilha criada para este fim, que consiste em uma matriz composta por linhas e colunas em que na primeira etapa as linhas continham as categorias e as colunas os entrevistados conforme o Quadro 3.

Quadro 3: Descrição das categorias

\begin{tabular}{|l|l|l|l|l|l|l|l|l|l|l|}
\hline & E1 & E2 & E3 & E4 & E5 & E6 & E7 & E8 & E9 & E10 \\
\hline $\begin{array}{l}\text { A política nacional de descentralização de } \\
\text { fomento à C\&T }\end{array}$ & & & & & & & & & & \\
\hline $\begin{array}{l}\text { O impacto das relações intergovernamentais } \\
\text { na PC\&T }\end{array}$ & & & & & & & & & & \\
\hline A institucionalização da PC\&TT & & & & & & & & & & \\
\hline $\begin{array}{l}\text { Percepções sobre o impacto das decisões } \\
\text { PC\&TT }\end{array}$ & & & & & & & & & \\
\hline
\end{tabular}

Fonte: Elaboração própria, com base em Bardin (2011).

Na segunda etapa, a matriz foi estruturada da seguinte forma: as linhas continham o 
nome dos entrevistados e as colunas os temas. A partir da aplicação de filtros nas células: identificação dos entrevistados, "assuntos levantados" e "definição das unidades de análise" foi possível identificar a presença, ausência, recorrência, intensidade, direção, ordem, sentido e definição dos índices, conforme o Quadro 4.

Quadro 4: Estrutura de análise da segunda etapa

\begin{tabular}{|l|l|l|l|}
\hline Identificação dos entrevistados & Assuntos levantados & Extrato da fala dos entrevistados & Definição das unidades de análise \\
\hline E1 & & & \\
\hline E10 & & & \\
\hline
\end{tabular}

Elaboração própria, com base em Bardin (2011).

Como pode ser observado, foi possível identificar além dos assuntos, as presenças, as ausências e a intensidade de cada um dos argumentos levantados por entrevistado e por categoria. Ao final foi elaborado o Quadro 4, o qual apresenta uma síntese para cada uma das categorias. A partir do quadro síntese concluiu-se a fase de coleta e tratamento dos dados, em que, de posse do referencial teórico, da análise documental e da análise de conteúdo foi possível analisar os dados posicionando-se em relação ao problema de pesquisa.

\section{A POLÍTICA DE CIÊNCIA E TECNOLOGIA NO ESTADO DO TOCANTINS: CONDICIONANTES IN- TERNOS}

O Tocantins é o mais novo estado da Federação, faz parte da região norte, seus limites geográficos estão desenhados a nordeste, com o Maranhão; a leste, com o Piauí; a sudeste, com a Bahia; a norte com Goiás; a sudoeste com Mato Grosso e a noroeste com o Pará.

De acordo com Rodrigues R., (2005) nos anos iniciais do Estado do Tocantins o desafio foi desenhar um modelo de crescimento econômico que assegurasse uma distribuição mais equitativa dos investimentos e melhorasse a distribuição da atividade econômica ao longo do espaço tocantinense.

De acordo com os estudos realizados por Rodrigues R., (2005) houve nos primeiros anos de criação do estado algumas tentativas de constituição da PCTT. Em 1989 foi realizado um primeiro diagnóstico sobre a situação da C\&T no Estado, entretanto, a tentativa não teve sucesso e nada foi formalizado.

Em 21 de fevereiro de 1990 foi criada a Universidade do Tocantins (UNITINS). Em 1992, em função dos escassos recursos financeiros e pela ausência de pesquisadores no Ruraltins, o governo realizou uma tentativa de criar o Instituto de Pesquisa Agropecuária do Tocantins (IPEATO), mas a tentativa foi frustrada. Desta forma, neste mesmo ano, a responsabilidade pela coordenação e execução das pesquisas no estado foi transferida para a UNITINS (RODRIGUES R., 2005).

Em 2000, ocorreu o processo de federalização da UNITINS e o Estado passa a contar com mais uma instituição de ensino superior, pois a UNITINS não deixou de existir com a criação da Fundação Universidade Federal do Tocantins. As duas instituições passaram a manter estruturas separadas, dinâmicas e de igual importância para o estado, inclusive 
podendo estabelecer convênios, parcerias, acordos de cooperação técnica, para juntas trabalharem em prol da sociedade (RODRIGUES R., 2005).

Somente depois de 17 anos de criação do Estado do Tocantins é que a SECT foi incorporada à estrutura do governo, por meio do Decreto $n$ ㅇ 2.588 , datado de 30 de novembro de 2005. Desta forma, as principais atribuições desta pasta consistiam em supervisionar e acompanhar a PCTT, fomentar atividades de pesquisa científica e tecnológica e a formação e aperfeiçoamento de pesquisadores em conjunto com as universidades. No rol de responsabilidades da recém-criada secretaria estava a de instituir o CECT.

No ano seguinte, no dia 1ㅇ de fevereiro de 2006 foi nomeado o primeiro secretário, João Leite Neto, até então a secretaria existia apenas no organograma do governo, a estrutura física ainda não fora implantada. No mesmo mês, por meio da Lei № 1.664/2006, foi instituído o CECT com o objetivo de formular as diretrizes e promover a execução da PCTT, bem como a de gerir o Fundo Estadual de Ciência e Tecnologia (FECT) que viria a ser criado posteriormente.

Em 8 de março do mesmo ano, houve a primeira reestruturação da secretaria, por meio do Decreto no 2.894, o CECT e a UNITINS passaram a estar vinculados à SECT. Em 3 de janeiro de 2007, ocorre a primeira mudança de secretário, desta vez assume o senhor José Augusto Pires Paula, que permaneceu no cargo por apenas quatro meses, assim, em 26 de abril, assume a secretaria o senhor Osmar Nina Garcia Neto.

Em 12 de novembro de 2007 foi publicada a Lei no 11.540, que dispõe sobre o FECT, renovando o Decreto-Lei no 719/1996 e a Lei no 9.478/1997, seu objetivo foi instituir o Conselho Diretor, definir a fonte de receita para constituição do fundo e definir a aplicação dos recursos.

Em 14 de setembro de 2009, assume a secretaria a senhora Maria Fernanda Varanda Carneiro, que permanece no cargo por 6 meses. Em 31 de março de 2010 é nomeada ao cargo de secretária, Márcia Izabel Barbosa Soares. No dia 10 de janeiro de 2011 a SECT é novamente reestruturada. Na nova proposta, lança-se ao desafio de captar e difundir novas tecnologias. Logo em seguida, em 2 de janeiro de 2011 assume a SECT o senhor Luiz Carlos Borges da Silveira.

Nesta gestão duas importantes medidas foram adotadas, a principal foi a criação da FAPT. Em 2011 só os estados do Tocantins, Roraima e Rondônia ainda não possuíam uma Fundação de Amparo à Pesquisa, desta forma, por meio da Lei complementar no 71 de 31 de maio de 2011 foi criada a mais nova Fundação de Amparo do país, a FAPT, com o objetivo de apoiar técnica e financeiramente projetos de difusão tecnológica, extensão, inovação e investigação desenvolvidos individualmente ou por instituições públicas e privadas sediadas no estado. Na ocasião foi constituído o Conselho Curador da FAPT, instância deliberativa da Fundação, e para presidi-la, no dia 7 de abril de 2011, foi nomeada a senhora Andrea Noleto de Souza Stival.

A segunda medida foi a criação da lei de inovação, outra adequação ao cenário nacional, assim, em 5 de julho do mesmo ano, por meio da Lei no 2.458 foi instituída a lei de inovação com o objetivo de incentivar a inovação e a pesquisa científica tecnológica nas atividades produtivas, com vistas à obtenção de autonomia, capacitação e competitividade no 
processo de desenvolvimento industrial do estado.

Depois de um período de importantes avanços, mesmo considerando a constante troca de secretários, constata-se que o cenário subsequente caminhou em direção oposta ao que havia sido desenhado para o Tocantins. Em 10 de outubro de 2012, assume a SECT, Andrea Noleto de Souza Stival, que passou a acumular a função de secretária e de presidente da FAPT.

Em 25 de fevereiro de 2013, por meio da medida provisória no 1, ocorre a fusão entre a Secretaria da Indústria e do Comércio com a Secretaria da Ciência e Tecnologia, a Secretaria das Cidades, Habitação e Desenvolvimento Humano. No mesmo dia, assume a recémcriada Secretaria de Desenvolvimento Econômico, Ciência, Tecnologia e Inovação (SEDEC$\mathrm{TI}$ ), o senhor Paulo Henrique Ferreira Massuia, que em 12 de abril também assume a presidência da FAPT.

A partir destas medidas, a estrutura da antiga SECTI foi reduzida a uma sala e a FAPT deixou de ter sede própria. Suas funções passaram a ser exercido pelos funcionários da SEDECTI, o único servidor ligado diretamente à FAPT era o próprio secretário.

Em 2014, depois do processo eleitoral, com um novo governo no poder, a SEDECTI deixa o status de secretaria e passa a ocupar posição hierárquica inferior identificando-se como Agência Tocantinense de Ciência, Tecnologia e Inovação - AGENTEC.

A partir da análise deste importante período percebeu-se que a PCTT passou por duas fases distintas como pode ser visualizada na figura que segue:

Figura 01: Fases da C\&T no Tocantins

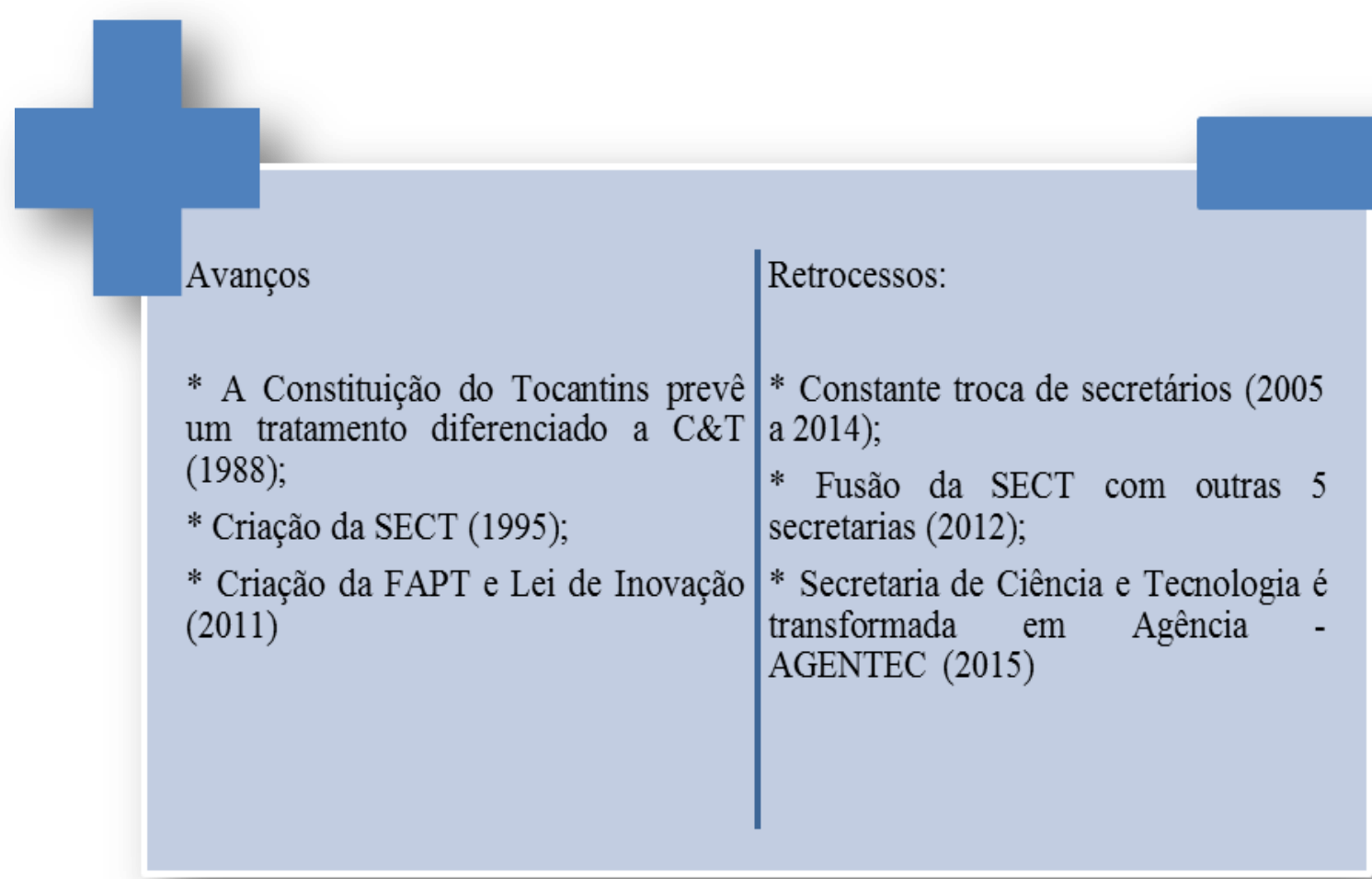

Fonte: Elaboração própria com base em dados da pesquisa 
As duas fases apresentadas demonstram claramente o impacto que as decisões dos gestores públicos exercem sobre a institucionalização de uma política pública. Sendo a C\&T estratégica para o desenvolvimento do Tocantins, o fato de ter sido relegada a terceiro ou quarto plano, leva a uma reflexão de que as oito principais características da boa governança definida por Nardes, Altounian e Vieira (2014) estavam ausentes e por isto fragilizou todo o processo de institucionalização da política.

A descontinuidade das ações empreendidas na política de C\&T no Estado do Tocantins, e a ausência da consolidação da estrutura básica para o desempenho organizacional dos órgãos vinculados à política de C\&T no estado do Tocantins, evidenciam um grau elevado de fragilidade estrutural da governança na política avaliada.

No próximo capítulo serão apresentadas as percepções dos entrevistados sobre a capacidade financeira do Tocantins de propor políticas com recursos próprios, bem como os fatores que interferem na tomada de decisão em relação às políticas que serão apoiadas e implementadas.

\subsection{Reflexões sobre a governança da ciência e tecnologia no Tocantins}

Neste tópico buscou-se avaliar as características da governança na PCTT, a partir do modelo de gestão existente nas instituições formais, e ainda pretende-se identificar o estágio, se inicial, intermediário ou avançado.

O estudo da Política de Ciência e Tecnologia no Tocantins teve como recorte temporal os anos entre 2005 e 2015, nesta perspectiva inicia-se a discussão com a descrição dos marcos institucionais da política, a partir da fala do entrevistado E7 (2015)

[...] Vamos pela ordem, a secretaria foi criada pelo governo Marcelo Miranda isto já foi um ganho institucional [...] na época não houve uma leitura correta sobre isto, mas como eu falei, só em ter criado já é um pequeno avanço, outro momento importante, foi a criação da FAPT, isto no governo "Siqueira Campos", aí na gestão do "Borges da Silveira", aquele momento o avião preparou para decolar, aquele momento foi importante, ele criou a Fundação, a lei de inovação, houve uma movimentação da comunidade acadêmica para criar a Fundação, um abaixo assinado, que nasceu da UFT. [...] Ele colocou para funcionar o Conselho Estadual de C\&T [...].

O que foi colocado pelo entrevistado E7 (2015) é que a criação da SECT, do CECT e da FAPT representou um momento em que o Tocantins alcançou um nível elevado de institucionalização em que tanto as instituições formais exerceram o seu papel no sistema democrático, e com isto possibilitou que a PCTT alcançasse níveis de consolidação próximos aos dos estados mais desenvolvidos.

De acordo com os entrevistados, a decisão de unir a C\&T com outras áreas em uma mesma secretaria não contou com a participação popular, e para $80 \%$ dos entrevistados representou uma medida desastrosa.

Esta constatação evidencia claramente a desobediência a um dos princípios da governança que diz respeito à legitimidade das ações do governo. Na percepção dos entrevistados as decisões que foram tomadas não representam a vontade do povo. 
Para Evans (2003) a garantia da governança precede a presença de instituições deliberativas, pois segundo o autor, a participação da sociedade nas decisões do estado é muito importante para a garantia da sua efetividade. Quando as instituições são investidas de capacidade institucional ocorre sucessivamente um melhoramento da gestão.

O CECT compreende um espaço de deliberação, e como tal foi projetado para se pensar as ações do governo de forma a estruturar o Estado na condição de indutor da PCTT, provendo os meios para que os diferentes atores: governo, universidades e empresas sejam cooperadores para que o Estado cumpra o seu papel de garantidor da qualidade de vida e do desenvolvimento da região.

Ao observar a composição do Conselho percebe-se que a realidade é bem diferente do que foi idealizado e do que preconiza a teoria da governança. No que se refere à paridade, dos 13 membros do Conselho, 8 são representantes do governo, o que compromete diretamente os resultados de suas decisões. No que se refere à legitimidade das decisões:

[...] O Conselho discutia especificamente aquele conjunto de ações que estavam dentro, no âmbito próprio do Conselho, e nós como entidade representando o setor industrial, não concordamos muitas vezes com os recursos que eram destinados, lembrando que tem composição de membros do próprio governo dentro do Conselho $[\ldots](\mathrm{E} 6,2015)$.

Percebe-se na fala do entrevistado E6 (2015) que ainda existe uma distância significativa entre o ideal e o real. O ambiente é de disputa, cada membro do Conselho em busca dos seus próprios interesses, esquecendo-se que o ganho só pode ser alcançado por meio da cooperação em favor do desenvolvimento regional.

No que se refere ao investimento em capital social, que se constitui elemento importante aos princípios da boa governança, constatou-se que a estrutura de governança descrita pelo entrevistado E4 (20015) não priorizou a permanência e capacitação de técnicos que pudessem dar sustentabilidade aos processos administrativos como pode ser evidenciado em sua fala "[...] Desde que foi criada a secretaria, houve uma rotatividade enorme de pessoas, então isto atrapalha demais o desenvolvimento de questões administrativas, burocráticas que permeia a própria Ciência e Tecnologia [...]".

A preocupação com o modelo político vigente não é uma característica apenas do Tocantins, o modus operandi da política brasileira gera insegurança e preocupação por parte da sociedade como um todo, uma vez que busca a prevalência do bem comum sobre os interesses de pessoas ou de grupos (Matias-Pereira, 2010). A insegurança em relação à PCTT é maior devido às condições financeiras do Estado.

Como mecanismo de financiamento da PCTT foi criado o Fundo Estadual de Ciência e Tecnologia. A decisão do Tocantins de criar o FECT foi decisiva para que o mesmo pudesse conduzir suas próprias ações de C\&T a partir de recursos próprios ou em parceria com o governo federal. No entanto, a garantia legal de recursos para a PCTT não impediu as manobras que resultassem na prática de desvio de finalidade por parte do governo estadual. 
[...] A Constituição do Estado prevê que 0,5\% do orçamento tributário deve ser aplicado em ciência, tecnologia e inovação, contudo, apesar desta previsão, este fundo é apenas orçamentário, o que significa que ao longo do ano ele é contingenciado e nem sempre, ele é utilizado efetivamente no desenvolvimento da ciência, tecnologia e inovação, então não há garantias que este 0,5\% da arrecadação tributárias do Estado vai ser aplicado na Ciência e Tecnologia [...] (E4, 2015).

Esta prática parece ser utilizada por todas as gestões, de acordo com o entrevistado E10 (2015).

A grande dificuldade é você garantir, um exemplo: nós temos hoje algo em torno de quinze milhões de reais para o Fundo, isto no planejamento, entretanto, para a execução desse planejamento, um número bem inferior a isto pela situação do financeiro. Acabam-se definindo outras prioridades e o Fundo acaba não recebendo em sua totalidade os recursos, seria interessante se a gente conseguisse mecanismos né, técnico e jurídico, para garantir a efetividade desses recursos no Fundo, que o Conselho tivesse acesso e conseguisse efetivar este recurso, hoje poderia fazer uma diferença muito grande nas ações e no desenvolvimento das políticas de C\&T, diferença gigantesca [...].

Com este cenário a dependência do Estado na condução da PCTT é determinante, e com isto medidas que garantam a continuidade das ações precisariam ser pensadas e colocadas em práticas, a partir da cobrança mais contundente dos responsáveis pela política, que são os formadores de opinião, pois como consta da fala do entrevistado E8 (2015), os investimentos e os resultado da C\&T extrapolam o lapso temporal de um mandato.

[...] Na C\&T não existe uma perspectiva de curto prazo, e isto acaba não ficando muito em sintonia com o sistema político do país, que tem uma eleição de 2 em 2 anos, uma para prefeitura e outra para o governo estadual e presidente, então de 2 em 2 anos existe medição de força, de ideais, de confrontação de ideias, de ideologias, de propostas, e a C\&T é sempre um investimento de médio e longo prazo, então se você está sempre colocando a C\&T dependente de quem tá gerindo o Estado você fica muito dependente, e torcendo para que independentemente do que foi feito num eventual primeiro mandato, que o colega, caso tenha sido bem sucedido, que ele continue, para pelo menos ficar até 8 anos com perspectiva de continuidade, porque se ficar mudando de quatro em quatro anos, o gestor que assumir, pode simplesmente mudar tudo, e tudo que está sendo feito fica perdido, fica parado no meio do caminho, então isto é muito frágil, então o pessoal deveriam colocar gestores mais técnicos e que sempre fosse assim para ter continuidade, independentemente das ideias[...] (E8, 2015).

Conhecer o contexto social e político de decisões do governo estadual no período de 2005 a 2015 foi necessário para explicar, em alguma medida, as respostas dadas pelos entrevistados no que se refere ao processo de consolidação da PCTT.

O que pôde ser observado nos documentos analisados é que a demanda por uma legislação direcionada para o desenvolvimento da C\&T, em parte já foi atendida, restando agora transformar a legislação em ações concretas e não apenas simbólicas como as que vêm ocorrendo no Tocantins.

[...] Você precisa que o Estado crie as leis, crie a estrutura administrativa, para que possa colocar aquela lei em prática, não estou dizendo, não estou, talvez querendo discutir o que é certo e o que é 
errado, mas olha, o dispositivo legal, ele sozinho, ele não leva esta política para ponta. Você precisa que esta política deixe de ser intenção, vire realidade através da lei, e da lei, com a estrutura administrativa, colocada e prática [...] $(E 6,2015)$.

A governança pública para Nardes, Altounian e Vieira (2014) vem na busca da recomposição da relação entre o Estado e a sociedade, na recondução do poder social ao seu lugar de direito, na inovação da administração pública na prestação de serviços, na integração, compartilhamento e cooperação em rede, no auxílio ao estado, enfim a boa governança tem o propósito nobre de alicerçar o que às reformas administrativas e a legislação ainda não conseguiram modificar, a transposição de um estado com melhores convicções e valores políticos.

A leitura dos dados empíricos apontaram para o retrocesso da PCTT e as dificuldades ligadas à governança, que de acordo com Nardes, Altounian e Vieira (2014, p.157) implicam na (in)capacidade do governo de "avaliar, direcionar e monitorar a gestão das políticas e serviços públicos para atender de forma efetiva as necessidades e demandas da população". Para o entrevistado E7 (2015)

O governo estadual não faz a sua parte, não gasta de forma adequada os recursos da C\&T, isto sim, desde o início, mistura-se finalidades, eu tenho recurso da C\&T, então eu vou pagar a folha da secretaria " $x$ " e " $y$ ", eu vou também pagar o proeducar, e pouco é feito na finalidade da C\&T [...] (E7, 2015).

Para Spink e Teixeira (2012) é necessário que existam mecanismos legais e institucionais que limitem decisões políticas desta natureza, sem que tenham sido submetidas às regras democraticamente constituídas, para que os efeitos negativos não se voltem contra a sociedade.

Migrar da letra fria da lei para a real entrega de resultados não é tarefa simples: exige a criação de estruturas, modelos e processos organizacionais que permitam a maximização do emprego dos recursos por meio de instrumentos de delegação, sem perder de vista o prioritário atendimento dos interesses da sociedade, o "principal" de toda a engrenagem.

Estreitando a análise, observa-se que não é suficiente apenas o fortalecimento das instituições. Em um ambiente em que a liberdade de opinião e a participação social ainda são restritas é necessário que as instituições ou agências estatais estejam suficientemente investidas de capacidades institucionais para harmonizar as relações sociais e garantir, assim, a integridade do bem comum (SPINK; TEIXEIRA, 2012).

Se para o autor, com a presença das instituições a participação dos mecanismos de intervenção popular é restrita, na sua ausência a situação da C\&T no Tocantins torna-se largamente afetada.

Para Slomski et al., (2008) o princípio da boa governança visa obter como resultado a implantação do monitoramento das políticas públicas, que por sua vez exige a aplicação de princípios constitucionais como a transparência, a prestação de contas, a redução de despesas públicas, a revisão e qualidade do gasto, o combate à corrupção, o investimento em pessoas, a participação e principalmente o restabelecimento da confiança pública. 
Utilizando-se mais uma vez das contribuições de Nardes, Altounian e Vieira (2014, p.157) quanto melhor for a capacidade de avaliar, mais efetivo serão os resultados das políticas definidas pelos governos, uma vez que os recursos serão empregados sem desperdício, os espaços de corrupção serão pequenos e as pessoas capacitadas serão escolhidas para conduzirem as ações necessárias.

A seguir são apresentadas as considerações finais.

\section{CONSIDERAÇÕES FINAIS}

Este artigo teve como objetivo avaliar o estágio de governança da Política de Ciência e Tecnologia do Tocantins, bem como identificar os seus avanços e retrocessos no período de 2005 a 2015.

A partir dos resultados obtidos foi possível identificar que a política de C\&T, no período analisado, apresentou avanços significativos com a criação da SECT, CECT, FECT e FAPT, estas suficientemente investidas de capacidade institucional tendem a apresentar níveis intermediários de governança.

No entanto, as medidas que resultaram na desarticulação dos quatro mecanismos citados apontam para um cenário de crise, pois não se pode falar de capacidade institucional sem a presença das instituições.

Percebe-se, no entanto, que mesmos diante de várias decisões de descontinuidade, como no caso das constantes trocas de secretários e da ausência de um quadro técnico próprio, se as instituições tivessem sido mantidas, poder-se-ia estar discutido outros aspectos da governança ligados ao processo de amadurecimento institucional, ou seja, a qualidade da governança (boa, regular ou ruim), como o que está acontecendo nos demais estados da Federação.

Enquanto os outros estados estão em busca de consolidação de suas instituições e na internacionalização de ações voltadas para C\&T, no Tocantins, ao contrário, discutem-se situações que já haviam sido superadas e que voltam à pauta de discussões, vez que se encontram no estágio inicial da política como demonstrado na discussão dos dados.

Outro aspecto importante presente nos fundamentos da governança que pode ser observado a partir dos resultados obtidos está relacionado à legitimidade das ações do governo, foi possível perceber que a comunidade científica, representada pelo CECT não foi consultada quanto à melhor decisão a ser tomada em momento de crise financeira que o estado do Tocantins hipoteticamente estivesse atravessando. Ao que foi diagnosticado, no processo de tomada de decisão não houve a participação da sociedade, no caso em específico, por meio do CECT, portanto, infere-se que não houve legitimidade na tomada de decisões.

O Estado do Tocantins possui particularidades que devem ser consideradas, o fato de ser um estado novo, com capacidade financeira limitada, aliada a má gestão dos recursos pelo governo estadual, fez com que a Política de C\&T ficasse limitada a resultados que não impactam na economia local, e por consequência, influencia na decisão do gestor. Este aspecto pode ter levado o governo estadual a optar por políticas assistencialistas e prefe- 
rido reduzir os investimentos em C\&T por considerá-la como um custo e não como investimento.

O impacto das decisões do governo do Tocantins provocou o afastamento da política de Ciência e Tecnologia estadual da política de descentralização do governo federal. Se os recursos já eram escassos com a presença da SECT e FAPT, com a desativação das mesmas a situação tende a piorar vez que o Tocantins terá limitações institucionais para acessar os recursos do governo federal.

Muitos foram os (des)caminhos identificados na Política de Ciência e Tecnologia do Tocantins. Porém, verifica-se que os contornos delineados podem ser reconstruídos e principalmente restabelecidos com o objetivo de tornar as instituições aqui avaliadas responsáveis pelas suas ações e inações.

O que foi possível constatar é que a governança da Política de Ciência e Tecnologia no estado está em estágio inicial.

Diante da desestruturação das instituições formais sugere-se que se desenvolvam mecanismos que objetivem controlar as ações do estado diante da descontinuidade de uma política tão relevante para o desenvolvimento em nível estadual e do próprio país, por intermédio da participação da sociedade, e principalmente dos atores locais envolvidos no controle da PCTT.

Recomenda-se ainda que outras pesquisas com este tema sejam realizadas, com o desígnio de entender melhor o processo de tomada de decisão desta política mediante a teoria do controle social exercido pela sociedade sobre o Estado e pelo Estado sobre si mesmo.

\section{REFERÊNCIAS}

BAUMGARTEN, M. O debate público de ciência e Tecnologia divulgação, difusão e popularização. In: Kerbauy, M. T. M. Andrade, T. H. N. \& Hayashi, C. R. M. (org). Ciência, Tecnologia e Sociedade no Brasil. Campinas - São Paulo: Alínea. Cap. 2, pp. 27-49. 2012.

BENAKOUCHE, T. A Contribuição da Teoria Sociológica para o Desenvolvimento dos Estudos em Ciência, Tecnologia e Sociedade. In: Kerbauy, M. T. M. Andrade, T. H. N. \& Hayashi, C. R. M. (org). Ciência, Tecnologia e Sociedade no Brasil. Campinas - São Paulo, Alínea. Cap. 1, pp. 13-25. 2012.

CABRERO, E.; VALADÉS, D.; LOPEZ-AYLLON S. El diseño institucional de la política de ciência y tecnologia em México. México: CIDE. 2006.

CANALES, A. La política científica y tecnológica em México: IISUE. 2011.

CENTRO DE GESTÃO E ESTUDOS ESTRATÉGICOS. Plano de Ciência, Tecnologia e Inovação para o Desenvolvimento da Amazônia Legal. CGEE. Brasília. 2013.

CHAIMOVICH, H. Brasil, Ciência, Tecnologia: Alguns dilemas e desafios. [online] Estudos Avançados, São Paulo, v. 14, no 40, pp. 134-143, Set./Dez. 2000.

COLOGNESE, S.; MELO, J. A técnica de entrevista na pesquisa social. Cadernos de Sociologia. v. 9, Porto Alegre: UFRGS. 1998.

EVANS, P. Além da "monocultura institucional": instituições, capacidades e desenvolvi- 
mento deliberativo. Revista Sociologias, Porto Alegre: PPGS/UFRGS, ano 5, n. 9, jan./jun. 2003.

LINDBLOM, C. O processo de decisão Política. Brasília: Editora UnB. 1981.

WIKIPEDIA. Lista de instituições de ensino superior do Brasil. Disponível em: <http:// pt.m.wikipedia.org/wiki/Lista_de_instituições_de_ensino_superior_do_Brasil >. Acesso em: 02/08/2016. 2016.

MATIAS-PEREIRA, J. Governança no setor público. São Paulo: Atlas. 2010.

NARDES, J., ALTOUNIAN, C.; VIEIRA, L. Governança Pública: o desafio do Brasil. Belo Horizonte: Fórum. 2014.

RODRIGUES. E. Análise da Ambiência Institucional de Ciência, Tecnologia e Inovação (C, T \& I). 136 f. 2013. Dissertação (Mestrado em Desenvolvimento Regional) - Programa de Mestrado em Desenvolvimento Regional da Universidade Federal do Tocantins, Tocantins, 2013.

RODRIGUES, R. A organização do sistema de ciência e tecnologia no Tocantins: evoluções e problemas. (Online). 89 f. 2005. Dissertação (Mestrado em Política Científica) - Instituto de Geociência da Universidade Estadual de Campinas, São Paulo, 2005.

ROSENAU, J. Governança, Ordem e Transformação na Política Mundial. In: Rosenau, J. N. e Czempiel, E. O. Governança sem governo: ordem e transformação na política mundial. Brasília: Ed. UnB e São Paulo: Imprensa Oficial do Estado. Pp. 11-46. 2000.

SLOMSKI, V. et al. A Governança e reformas da administração pública. São Paulo. Editora: Atlas. 2008.

SPINK, P.; TEIXEIRA, M. Controle social e controle institucional: um diálogo necessário. In: Carneiro, J. M. B \& Dantas, H. (orgs.). Parceria social público-privada: textos de referência. -- São Paulo: Oficina Municipal. Cap. 17. 359-373. 2012.

TRIBUNAL DE CONTAS DA UNIÃO. Referencial Básico de Governança: Aplicável a Órgãos e Entidades da Administração Pública. TCU. Brasília. 2013.

TRIBUNAL DE CONTAS DA UNIÃO. TC 000.390/2010-0. TCU. Brasília. Disponível em: < portal.tcu.gov.br/lumis/portal/file/fileDownload.jsp?fileld>. Acesso em: 25/10/2015.

TRIGUEIRO, M. Sociologia da Tecnologia: Bioprospecção e legitimação. São Paulo: Centauro. 2009.

TRIVIÑOS, A. Introdução à Pesquisa de Ciências Sociais. São Paulo, Atlas. 175p. 1987.

VIEIRA, D. A Guerra fiscal no Brasil: caracterização e análise das disputas interestaduais por investimentos em período recente a partir das experiências de MG, BA, PR PE E RJ. In: Aristides Monteiro Neto (Org). Governos estaduais no federalismo brasileiro: capacidades e limitações governativas em debate. Brasília: Ipea. Cap. 4. pp. 145-179. 2014. 